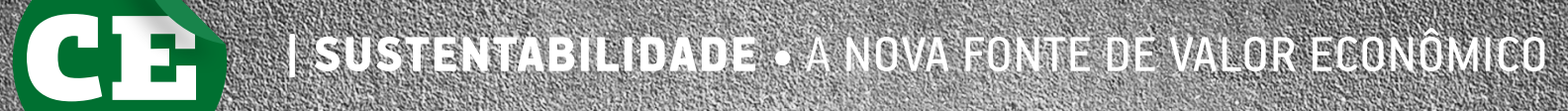

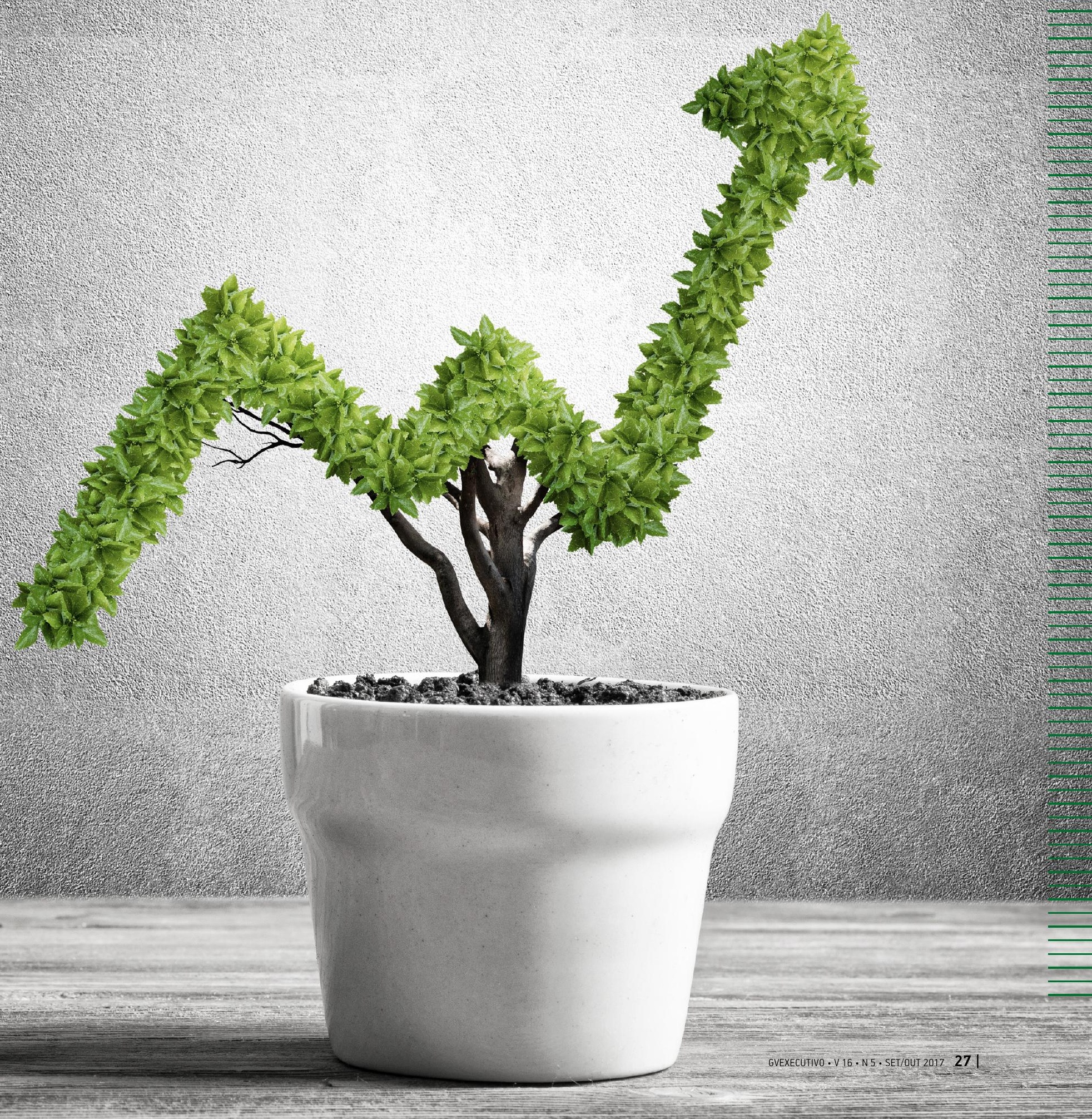




\section{A NOVA FONTE DE DE VALOR ECONÔMICO}

\section{Uma gestão que incorpore aspectos socioambientais será cada vez mais fundamental para criar e proteger o capital das empresas.}

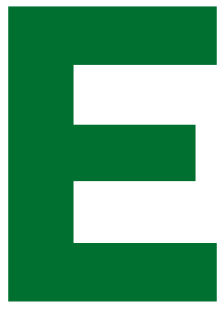

mpresas bem-sucedidas estão acostumadas a lidar com mudanças e incertezas. Investem em inovação, muitas vezes com resultados futuros incertos e com sacrifício de recursos financeiros no curto prazo. Seus gestores são capazes de enxergar oportunidades para criação e proteção de valor econômico em um horizonte de tempo mais longo.

Mas vislumbrar o futuro não é fácil. Diversos aspectos podem dificultar esse processo, como a falta de algum recurso ou capacidade e a dependência de escolhas realizadas no passado. Há ainda causas sutis que podem dificultar a leitura de um contexto em transformação. Acreditamos que, quando o assunto é sustentabilidade, isso acontece principalmente por causa das origens desse termo.

Sob a complexidade do termo "sustentabilidade" estão abrigados temas com origens nos anos 1960 e 1970, quando a ecologia saiu do âmbito acadêmico e se tornou bandeira de movimentos sociais. Ao longo de décadas, essa agenda foi evoluindo e incorporando um novo vocabulário. Ao repertório ambientalista do "natural", “orgânico", “ecológico", "verde", "biodegradável", "reciclável" e "renovável" foram se unindo termos oriundos da responsabilidade social empresarial, chegando-se ao "sustentável".

Essa trajetória - em que argumentos científicos se mesclam com convicções éticas e diferentes visões de mundo - faz com que muitos observadores do campo empresarial ainda vejam na sustentabilidade apenas uma bandeira ideológica, descartando-a pelo valor de face. Porém, independentemente de sua origem, no termo sustentabilidade está contido um conteúdo de extrema relevância para o futuro (e o presente) dos negócios. Com a sustentabilidade, produzir e vender não são mais suficientes. Não importa apenas ter lucro, mas saber como esse lucro foi gerado. A gestão que incorpora a sustentabilidade é, hoje, rota fundamental para a criação e a proteção de valor econômico.

Esse também é o entendimento de quem ganha a vida identificando, mensurando, monitorando, reportando, controlando e mitigando riscos: o sistema financeiro. 
SISTEMA FINANCEIRO E SUSTENTABILIDADE

No âmbito global, não é nova a compreensão por parte de agentes do setor financeiro de que aspectos socioambientais representam importantes fontes de riscos para atividades de crédito e investimentos. Essa visão pode ser organizada em dois grandes momentos, que formam um continuиm: o primeiro, por volta do ano 2000 - mas com ações antes disso -, é caracterizado pela disseminação de códigos de conduta voluntários, em que aspectos socioambientais são considerados elementos importantes na tomada de decisão por agentes do setor. Já no segundo momento, com a Rio+20 (2012), a discussão de risco socioambiental entra com força na agenda de supervisores e reguladores do sistema financeiro, somando-se aos códigos voluntários.

Dois marcos destacam-se como exemplos do primeiro momento. Um, em 2003, é o surgimento dos Princípios do Equador, um framework para gestão de risco socioambiental adotado por instituições financeiras voltadas ao mercado de crédito. Atualmente, 91 instituições financeiras em 37 países são signatárias dessa iniciativa. O outro, em 2006, é o lançamento dos Princípios para o Investimento Responsável (PRI, na sigla em inglês), uma iniciativa voltada à comunidade de investidores sob o guarda-chuva da Organização das Nações Unidas
(ONU). Os signatários do PRI devem, entre outros aspectos, comprometer-se a incorporar a análise social, ambiental e de governança no processo de tomada de decisão, assim como exigir das empresas investidas transparência quanto a esses mesmos atributos. Atualmente, o PRI possui 1.700 investidores signatários com ativos sob gestão de cerca de US\$ 60 trilhões.

As bolsas de valores são outro exemplo. Desde o surgimento, em 1999, do pioneiro Dow Jones Sustainability Index (DJSI), foram criados, pelo menos, outros 35 índices de sustentabilidade relacionados ao mercado de ações. O Brasil foi um dos pioneiros no campo ao lançar, em 2005, a quarta iniciativa nessa categoria, por meio de seu Índice de Sustentabilidade Empresarial (ISE), que reflete a valorização de uma carteira teórica composta por ações de até 40 empresas, selecionadas anualmente por um amplo conjunto de critérios relacionados à sustentabilidade. Ao longo dos 12 anos de existência do ISE, 142 empresas buscaram integrar sua carteira, sendo que 72 delas foram selecionadas em pelo menos um ano. Nesse mesmo período, o ISE apresentou valorização de $173,8 \%$, bem acima dos $121,9 \%$ obtidos pelo Índice da Bolsa de Valores de São Paulo (Ibovespa), o indicador do desempenho médio das cotações dos ativos de maior negociabilidade e representatividade do mercado de ações brasileiro.

\section{COMPARAÇÃO DE RENTABILIDADE ENTRE 0 ÍNDICE DE SUSTENTABILIDADE EMPRESARIAL (ISE) E 0 ÍNDICE DA BOLSA DE VALORES DE SÃO PAULO (IBOVESPA)}

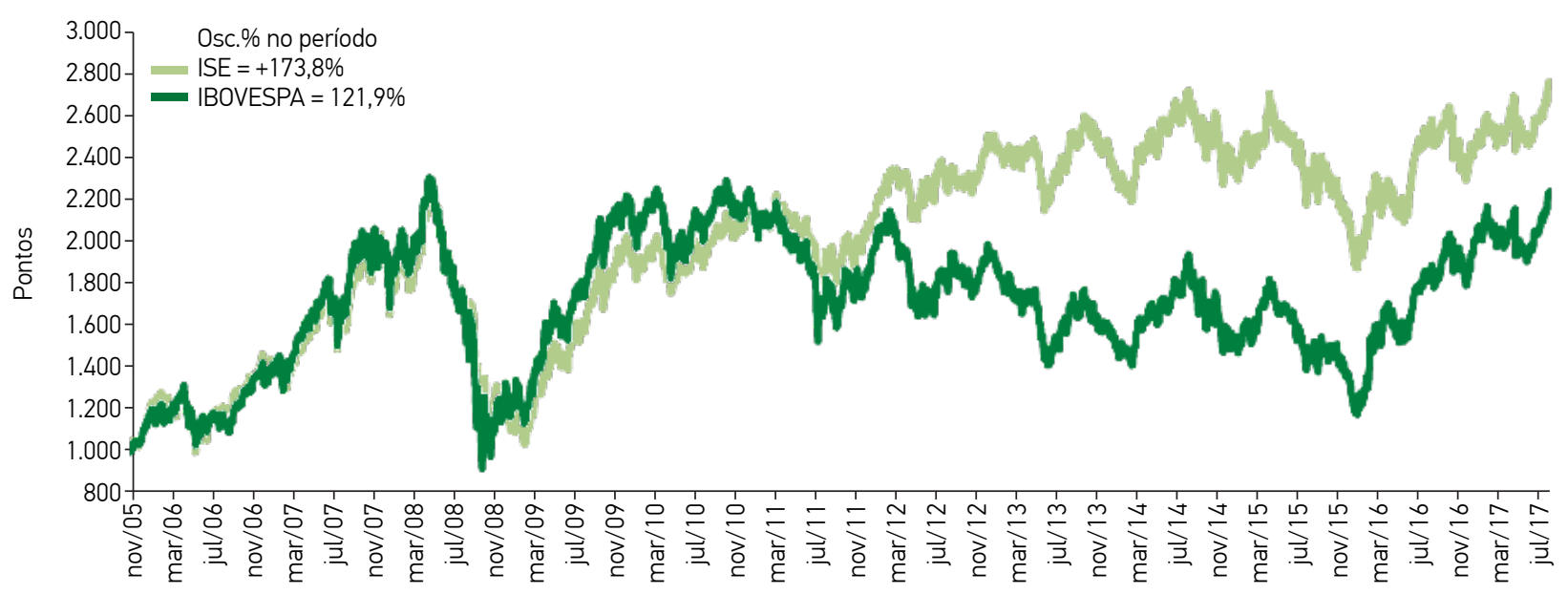

\footnotetext{
FONTE: BOLETIM ISE, AGOSTO 2017. 


\section{O QUE OS INVESTIDORES DEVEM ANALISAR QUANTO AOS RISCOS CLIMÁTICOS DAS EMPRESAS}

\begin{tabular}{|c|c|}
\hline Dimensão da gestão & Governança \\
\hline $\begin{array}{l}\text { Análises a serem } \\
\text { realizadas pelos } \\
\text { investidores nas } \\
\text { empresas-alvo de } \\
\text { investimentos ou já } \\
\text { investidas }\end{array}$ & $\begin{array}{l}\text { Análise da governan- } \\
\text { ça da organização em } \\
\text { torno de riscos e opor- } \\
\text { tunidades relacionados } \\
\text { ao clima. }\end{array}$ \\
\hline
\end{tabular}

Dimensão da gestão
Estratégia

Gestão de risco

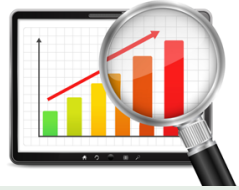

Métricas e metas
Análise dos impactos reais e potenciais dos riscos e oportunidades relacionados ao clima nos negócios, na estratégia e no planejamento financeiro da organização.
Análise de como a orga- Análise das métricas e metas usanização identifica, ava- das pela organização para avaliar lia e gerencia os riscos e gerenciar riscos e oportunidades relacionados ao clima. relevantes relacionados ao clima.

- A empresa possui um processo para identificar e avaliar os riscos associados à mudança do clima? E para gerir esses riscos?

- Como se dá esse processo?

Como o processo para identificar, avaliar e gerir tais riscos são integrados na estrutura geral de gerenciamento de riscos da organização?
- Quais métricas são utilizadas para avaliar riscos e oportunidades associados à mudança do clima? Como tais métricas estão alinhadas com a estratégia e o processo de gestão de riscos da empresa?

- Quais são as emissões de gases de efeito estufa da empresa nos escopos 1, 2 e 3 do GHG Protocol? E quais os riscos relacionados? - Quais são as metas utilizadas pela empresa para gerir esses riscos e oportunidades? E como tem sido a performance da empresa em relação a essas metas?
No segundo momento, o maior destaque foi o envolvimento do Financial Stability Board (FSB) em relação à exposição do setor financeiro ao risco climático. O FSB é um organismo internacional que monitora e faz recomendações visando à estabilidade e à resiliência do sistema financeiro global. Alguns dos principais papéis do FSB são identificar riscos sistêmicos que afetam o sistema financeiro, recomendar políticas públicas que mitiguem tais riscos e supervisionar a implementação dessas políticas. Os membros do FSB são os bancos centrais, ministérios da fazenda e demais integrantes do sistema financeiro.

O FSB considera que as mudanças climáticas representam uma ameaça material para o sistema e, consequentemente, entende que os investidores precisam ter acesso a informações ligadas aos riscos climáticos das empresas, para que seus cálculos incorporem essa nova categoria. Nesse sentido, o FSB publicou, em junho de 2017, recomendações sobre os elementos que devem ser observados por investidores, tanto em relação aos riscos físicos (operações que podem ser afetadas fisicamente pelas mudanças do clima) quanto em relação aos riscos associados à transição para uma economia de baixo carbono (que incluem mudanças tecnológicas e impactos de políticas públicas) - leia mais detalhes sobre essas orientações no quadro.

Os objetivos do FSB são, ainda, mapear a concentração de ativos no sistema financeiro dependentes de altas emissões de carbono (chamados de carbon-related assets) e, por consequência, avaliar a exposição do sistema financeiro global ao risco climático. As recomendações do FSB tendem a ser rapidamente incorporadas por bancos comerciais e de investimentos, bem como por seguradoras do mundo todo. Sua adoção também deverá gerar grande efeito nas empresas não financeiras, que serão chamadas a prestar informações que hoje desconhecem.

Em nosso país, o Banco Central do Brasil (Bacen) tem avançado na regulação de temas socioambientais. São três as 


\section{Com a sustentabilidade, produzir e vender não é mais suficiente. Não importa apenas ter lucro, mas saber como esse lucro foi gerado.}

principais razões para isso: mitigação de riscos, maior integração do sistema financeiro com as demais políticas públicas socioambientais do país e busca por mais eficiência no setor. Nesse esforço, duas resoluções do Bacen destacam-se: 1. Resolução n. 4.327 , de abril de 2014 , que estabelece que as instituições financeiras devem ter uma política de responsabilidade socioambiental e observar aspectos materiais para o risco da instituição;

2. Resolução n. 4.557 , de fevereiro de 2017 , que inclui riscos socioambientais na estrutura de gestão de riscos das instituições financeiras.

Também nesse segundo momento, os esforços voluntários do mercado brasileiro no sentido da sustentabilidade continuaram avançando. A Federação Brasileira de Bancos (FEBRABAN), entidade representativa do setor bancário brasileiro, vem se debruçando sobre a importância econômica de aspectos socioambientais. Como exemplo de seus esforços recentes nesse sentido, destaca-se a metodologia desenvolvida em parceria com o Centro de Estudos em Sustentabilidade (GVces) da Escola de Administração de Empresas de São Paulo da Fundação Getulio Vargas (FGV EAESP), que é pioneira no mundo e destinada à criação de uma base de dados sobre o volume de recursos canalizados para a chamada Economia Verde. Com a sistematização dessa informação, os bancos vão avançar na gestão de seus riscos socioambientais, identificar oportunidades de negócio ligadas à sustentabilidade, favorecer análises comparativas com outros países e contribuir para políticas públicas.

Além disso, em 2014, a FEBRABAN publicou uma norma autorreguladora que prevê diretrizes e procedimentos voltados a práticas socioambientais nas instituições financeiras. Entre outras discussões promovidas pela FEBRABAN, estão o financiamento de recomposição florestal, os títulos verdes e o risco de desmatamento em agropecuárias.

\section{UMA ROTA PARA O FUTURO}

Por que o setor financeiro está tão interessado na sustentabilidade? Por duas grandes razões. A primeira tem foco no momento presente: aspectos socioambientais podem representar riscos (impactos negativos sobre o fluxo de caixa) para as empresas que obtêm crédito e/ou investimentos, como perdas financeiras ou graves danos reputacionais por envolvimento em casos de corrupção, trabalho infantil ou análogo ao escravo, multas por não atendimento à legislação ambiental, entre outros. A segunda razão envolve a perspectiva futura da organização: a capacidade de a empresa se manter competitiva em um mundo que passa por profundas transformações. As decisões de investimentos e rotas tecnológicas feitas hoje terão impacto sobre a competitividade das empresas no médio e longo prazos. Por essa razão, se não considerarem elementos ligados à sustentabilidade - como mudanças climáticas -, podem tomar decisões que impactarão sua habilidade em se manter competitivas daqui a relativamente poucos anos.

Há uma conhecida frase atribuída a Benjamin Franklin que diz: "Ao falhar na preparação, você está se preparando para falhar". A gestão para a sustentabilidade mantém a empresa conectada com um mundo em transição e contribui para a melhor gestão de riscos. Na medida em que conhece mais profundamente impactos e dependências ligados a aspectos socioambientais materiais para seu negócio, mantém-se conectada às transições em curso, possibilitando inovações que contribuirão para seu sucesso futuro, com criação e proteção de valor econômico.

\footnotetext{
PARA SABER MAIS:

GVces e FEBRABAN. O sistema financeiro nacional e a economia verde. Alinhamento ao desenvolvimento sustentável, 2014. Disponível em:

sistema-financeiro-nacior

BM\&F Bovespa. Indice de Sustentabilidade Empresarial (ISE).

indices/indices-de-sustentabilidade/indice-de-sustentabilidade-empresarial-ise h

FSB Task Force on Climate-related Financial Disclosures (TCFD). Recommendations of the Task Force on Climate-related Financial Disclosures. 2017. Disponivel em: fsb-tcfd.org/ publications/final-recommendations-report/

ANNELISE VENDRAMINI > Professora e coordenadora do Programa de Finanças Sustentáveis do Centro de Estudos em Sustentabilidade (GVces) da FGV EAES P > annelise.vendramini@fgv.br

ARON BELINKY > professor e coordenador do Programa de Produção e Consumo Sustentáveis do Centro de Estudos em Sustentabilidade (GVces) da FGV EAESP > aron.belinky@fgv.br
} 